Sankyo Co., Ltd., Takeda Pharmaceutical Co., Ltd., AbbVie GK, Asahikasei Pharma Corp., Mitsubishi Tanabe Pharma Co., Pfizer Japan Inc., Eisai Co., Ltd., AYUMI Pharmaceutical Corporation, Nipponkayaku Co. Ltd., Novartis Pharma K.K., Grant/research support from: AbbVie, Asah Kasei, Astellas, AstraZeneca, AYUMI, Bristol-Myers Squibb, Chugai, Daiichi Sankyo, Eisai, Eli Lilly Japan, Janssen, Mitsubishi Tanabe, Nippon Kayaku, Novartis, Pfizer Japan Inc, Taiho, Taisho Toyama, Takeda, Teijin, Grant/research support from: Astellas Pharma Inc., Bristol Myers Squibb, Chugai Pharmaceutical Co., Ltd., Mitsubishi Tanabe Pharma Co., Pfizer Japan Inc., Santen Pharmaceutical Co., Ltd., Takeda Pharmaceutical Co., Ltd., Teijin Pharma Ltd., AbbVie GK, Asahi Kasei Pharma Corp., Taisho Toyama Pharmaceutical Co., Ltd., SymBio Pharmaceuticals Ltd., Janssen Pharmaceutical K.K., Celltrion Inc., Nipponkayaku Co. Ltd., and UCB Japan, Consultant for: Astra Zeneca K.K., Eli Lilly Japan K.K., Novartis Pharma K.K., Mitsubishi Tanabe Pharma Co., Abbivie GK, Nipponkayaku Co.Ltd, Janssen Pharmaceutical K.K., Astellas Pharma Inc., Taiho Pharmaceutical Co. Ltd., Chugai Pharmaceutical Co. Ltd., Taisho Toyama Pharmaceutical Co. Ltd., GlaxoSmithKline K.K., UCB Japan Co. Ltd., Consultant for: AbbVie, Asahi Kasei, Astellas, AstraZeneca, AYUMI, Bristol-Myers Squibb, Chugai, Daiichi Sankyo, Eisai, Eli Lilly Japan, Janssen, Mitsubishi Tanabe, Nippon Kayaku, Novartis, Pfizer Japan Inc, Taiho, Taisho Toyama, Takeda, Teijin, Consultant for: Astra Zeneca K.K., Eli Lilly Japan K.K., Novartis Pharma K.K., Mitsubishi Tanabe Pharma Co., Asahi Kasei Medical K.K., AbbVie GK, Daiichi Sankyo Co., Ltd., Bristol Myers Squibb, and Nipponkayaku Co. Ltd., Speakers bureau: Astellas Pharma Inc., Bristol Myers Squibb, Chugai Pharmaceutical Co., Ltd., Mitsubishi Tanabe Pharma Co., Pfizer Japan Inc., Santen Pharmaceutical Co., Ltd., Takeda Pharmaceutical Co., Ltd., Teijin Pharma Ltd., AbbVie GK, Asahi Kasei Pharma Corp., Taisho Toyama Pharmaceutical Co., Ltd., SymBio Pharmaceuticals Ltd., Janssen Pharmaceutical K.K., Celltrion Inc., Nipponkayaku Co. Ltd., and UCB Japan, Speakers bureau: AbbVie, Asahi Kasei, Astellas, AstraZeneca, AYUMI, Bristol-Myers Squibb, Chugai, Daiichi Sankyo, Eisai, Eli Lilly Japan, Janssen, Mitsubishi Tanabe, Nippon Kayaku, Novartis, Pfizer Japan Inc, Taiho, Taisho Toyama, Takeda, Teijin, Speakers bureau: AbbVie GK., Bristol-Myers K.K., Chugai Pharmaceutical Co. Ltd., Mitsubishi Tanabe Pharma Co., Pfizer Japan Inc., Astellas Pharma Inc, Diaichi Sankyo Co. Ltd., Eisai Co. Ltd., Sanofi K.K., Teijin Pharma Ltd., Takeda Pharmaceutical Co. Ltd., Novartis Pharma K.K. DOI: 10.1136/annrheumdis-2019-eular.1729

\section{FRI0093 IMPACT OF INTERLEUKIN 6 RECEPTOR INHIBITOR ON N-TERMINAL PRO-BRAIN NATRIURETIC PEPTIDE IN PATIENTS WITH RHEUMATOID ARTHRITIS}

Helen Gerasimova ${ }^{1}$, Tatiana Popkova ${ }^{1}$, Maria Cherkasova $^{1}$, Diana Novikova ${ }^{1}$, Galina Lukina ${ }^{2}$, Satenik Davidian ${ }^{3}{ }^{1}$ V.A.Nasonova Research Institute of Rheumatology, Moscow, Russian Federation; ${ }^{2}$ A.S. Loginov Moscow Clinical Research and Practical Center, Moscow Healthcare Department, Moscow, Moscow, Russian Federation; ${ }^{3} \mathrm{Federal}$ State Budgetary Institution "National Medical Surgical Center named after N.I.Pirogov", Moscow, Russian Federation

\section{Background:}

Objectives: To investigate the impact of interleukin 6 receptor inhibitor tocilizumab (TCZ) on NT-proBNP level changes in patients with rheumatoid arthritis (RA) during a 12- month (m) follow-up period.

Methods: The investigation enrolled 31 patients (pts) (26women/5men) with the lack of efficacy/resistance and/or intolerance of basic anti-inflammatory drugs (DMARDs); median age was 54[45; 61] years, median disease duration 10 [62;168]m; DAS28 6,2[5,1;7,1]; SDAI 35,0[23,9;51,0], CDAI 30,0[21,0;42,0], serum positivity for rheumatoid factor $(\mathrm{RF})(100 \%) /$ anti-cyclic citrullinated peptide antibodies (ACCP)(84\%). The study did not include RA pts with congestive heart failure. High incidence of traditional risk factors was found in RA pts: arterial hypertension - in $75 \%$, dyslipidemia - $61 \%$, smoking - $17 \%$, overweight - $61 \%$, family history of cardiovascular diseases - $36 \%$, hypodynamia - $68 \%$. Coronary artery disease was diagnosed in $11 \%$ RA pts. Lack of efficacy of 3 or more DMARDs was found in $46 \%$ of pts, intolerance to previous therapy with DMARDs - in $54 \%$ pts. These patients were administered TCZ $(8 \mathrm{mg} / \mathrm{kg})$ every 4 weeks: $39 \%$ were receiving TCZ monotherapy, and 61\% - TCZ in combination with methotrexate (20 $[18 ; 25] \mathrm{mg} /$ week). Serum levels of of NT-proBNP were measured using electrochemiluminescence method Elecsys proBNP II (Roche Diagnostics, Switzerland)

Results: Significant positive changes in major disease activity clinical and laboratory parameters were found in RA pts after $12 \mathrm{~m}$ of TCZ infusion: $54 \%$ of pts achieved remission (DAS28<2,6) and $46 \%$ of pts managed to decrease activity to low level (DAS28<3,2) with accompanying improvement in DAS28, levels of ESR, C-reactive protein (CRP), and RF (table 1).

\begin{tabular}{lccc}
\hline & Baseline & $12 \mathrm{~m}$ & $\mathrm{P}$ \\
\hline DAS 28 & $6,2[5,1 ; 7,1]$ & $2,7[1,5 ; 3,3]$ & $<0,001$ \\
ESR, mm/hr & $38[24 ; 54]$ & $8[4 ; 16]$ & $<0,001$ \\
CRB, mg/l & $27[10 ; 49]$ & $0,5[0,2 ; 0,7]$ & $<0,001$ \\
RF, IU/ml & $130[30 ; 564]$ & $38[23 ; 332]$ & HA \\
ACCP, IU/ml & $284[34 ; 300]$ & $112[32 ; 300]$ & HA \\
NT-proBNP, pg/ & $75,8[43,0 ;$ & $37,8[25,1 ;$ & 0,001 \\
ml & $100,7]$ & $78,5]$ & \\
\hline
\end{tabular}

TCZ therapy resulted in decrease of median NT-proBNP levels from 75,8 $[43,0 ; 100,7]$ to $37,8[25,1 ; 78,5] \mathrm{pg} / \mathrm{ml}(\mathrm{p}=0,01)$, while rate of elevated $(\geq 100 \mathrm{pg} / \mathrm{ml})$ NT-proBNP levels did not change (13\%). $\triangle \mathrm{NT}$-proBNP correlations of with $\triangle E S R(R=0,43 ; p<0,05]$ and with $\triangle C R B(R=0,46 ; p<0,05]$ were documented after $12 \mathrm{~m}$ of TCZ therapy. No direct correlation between $\triangle N T$-proBNP and changes in disease activity, or RF, or ACCP has been established. There was no noticeable differences in NT-proBNP levels in RA pts receiving TCZ monotherapy and TCZ in combination with methotrexate.

Conclusion: Obtained preliminary results show that $12 \mathrm{~m}$ of TCZ therapy resulted in decreased RA activity and lower levels of NT-proBNP on both regimens - mono - or combination $(\mathrm{TCZ}+\mathrm{MT})$ therapy.

Lowering NT-proBNP concentrations are associated with positive dynamics of inflammatory markers (CRP, ESR), therefore allowing to suggest increased NT-proBNP levels should be considered as a component of disease activity.

Disclosure of Interests: Helen Gerasimova: None declared, Tatiana Popkova: None declared, Maria Cherkasova: None declared, Diana Novikova None declared, Galina Lukina: None declared, Satenik Davidian Speakers bureau: Educational meetings organized or supported by companies. DOI: 10.1136/annrheumdis-2019-eular.5258

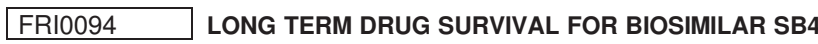 ETANERCEPT IN RHEUMATOID ARTHRITIS, PSORIATIC ARTHRITIS AND AXIAL SPONDYLOARTHRITIS PATIENTS WITH A NON-MEDICAL SWITCH FROM ETANERCEPT REFERENCE DRUG}

Glenn Haugeberg ${ }^{1}$, Bjørg Tilde Svanes Fevang ${ }^{2}$, Gunnstein Bakland ${ }^{3}$, Erik Rødevand ${ }^{4}$, Andreas Diamantopoulos ${ }^{5} .{ }^{1}$ Sørlandet Hospital Kristiansand, Rheumatology, Kristiansand, Norway, ${ }^{2}$ Haukeland hospital, Rheumatology, Bergen, Norway; ${ }^{3}$ University Hospital of North Norway HF, Rheumatology, Tromso, Norway, ${ }^{4}$ St. Olavs Hospital HF, Rheumatology, Trondheim, Norway, ${ }^{5}$ Martina Hansens Hospital, Rheumatology, Bærum, Norway

Background: In the new millennium biologic therapies e.g. tumor necrosis factor inhibitors (TNFi) have played a major role improving clinical outcomes in rheumatoid arthritis (RA), psoriatic arthritis (PsA) and axial spondyloarthritis (ax-SpA). A major limitation in many countries for prescribing these drugs has been the high drug costs. The patent period for several of these TNFis e.g. infliximab, etanercept and adalimumab has ended and as a consequence biosimilar TNFis are now reaching the market. This has a cost saving potential for payers. In Norway, encouraged by the health authorities, non-medical switch from originator to biosimilar has been performed in most patients on biologic originator drugs with biosimilar drugs available, including etanercept. To the best of our knowledge no longer than one year real life experienced real life evidence data for non-medical switch from originator etanercept to biosimilar etanercept SB4 exist (ref.1)

Objectives: To explore three-year drug survival for biosimilar SB4-etanercept in RA, PsA and ax-SpA patients with a non-medical switch from etanercept originator to SB4.

Methods: At the participating outpatient clinics patients with RA, PsA and ax-SpA are monitored using a clinical computer system, as standard clinical care. Demographic, clinical and treatment data were retrieved from the computer system for patients who started treatment with biosimilar etanercept SB4 between January 2016 and January 2019.

Kaplan-Meier survival curves were used to explore drug survival. Survival differences between groups were tested using Breslow statistics.

Results: At the participating outpatient clinics since 2016 a total of 474 RA, 249 PsA and 320 ax-SpA patients had a non-medical switch from etanercept originator to biosimilar etanercept SB4. In RA, PsA and ax$\mathrm{SpA}$ patients the percentage of women was $68.2 \%, 42.6 \%$ and $30.3 \%$, the percentage of current smokers $17.0 \%, 12.8 \%$ and $19.6 \%$, mean (SD) age was 63.0 (13.1), 58.2 (11.3), 53.1 (12.1) years and disease duration 16.8 (9.8), 16.1 (9.7), 17.7 (11.0) years, respectively. In RA 80.0\% were anti-CCP positive and in PsA and ax-SpA $34.4 \%$ and $90.8 \%$ were 
HLAB27 positive. In the table selected disease measures at baseline are shown.

\begin{tabular}{lccc}
\hline & RA & PsA & Ax-SpA \\
\hline DAS28 & $2.6(1.2)$ & $2.2(1.1)$ & - \\
ESR mm/hr & $15.9(15.1)$ & $12.2(13.9)$ & $12.0(15.1)$ \\
CRP mg/l & $4.9(8.6)$ & $4.3(7.6)$ & $5.5(10.3)$ \\
Fatigue (VAS 0-100) & $34.7(30.7)$ & $35.8(29.3)$ & $40.9(30.0)$ \\
Pain (VAS 0-100) & $31.3(23.8)$ & $31.2(24.1)$ & $33.7(24.6)$ \\
MHAQ & $0.42(0.47)$ & $0.37(0.40)$ & $0.40(0.40)$ \\
BASDAI & - & - & $3.1(2.3)$ \\
BASFI & - & - & $2.6(2.3)$ \\
\hline
\end{tabular}

No significant difference $(p=0.97)$ in drug survival for SB4 was seen between RA, PsA and ax-SpA patients. Mean $(95 \% \mathrm{Cl}) \mathrm{SB} 4$ drug survival time (years) was for RA 2.3 (2.2-2.4), for PsA 2.3 (2.2-2.4) and for ax-SpA 2.4 (2.3-2.5). In the figure below Kaplan-Meier drug survival curves are shown. Men had a statistically significant longer mean drug survival than women $(2.5(2.4-2.6)$ vs $2.2(2.1-2.3), p=0.001)$.

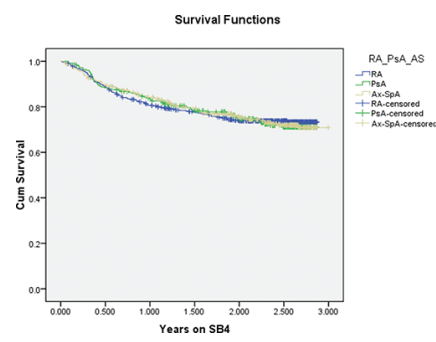

Conclusion: Our long term real life data show that the majority of patients with a non-medical switch from originator etanercept to biosimilar etanercept SB4 remained on the drug. No significant difference in drug survival was seen between RA, PsA and ax-Spa patients. Men however had a significantly longer drug survival than women. Further analyses are needed to explore reasons for cessation across gender and patient groups.

\section{REFERENCE:}

[1] Glintborg B et al. Ann Rheum Dis 2018;0:1-9

Disclosure of Interests: Glenn Haugeberg Grant/research support from: For this study grant from Biogen, Consultant for: Medical Advisory boards for several companies, Paid instructor for: I have been paid for giving lectures for pharmaceutical companies and their employees, Speakers bureau: I have been paid for giving lectures in meetings organized by pharmaceutical companies, Bjørg Tilde Svanes Fevang: None declared, Gunnstein Bakland: None declared, Erik Rødevand: None declared, Andreas Diamantopoulos: None declared DOI: 10.1136/annrheumdis-2019-eular.7387

\section{FRI0095 CHANGES IN B CELL PROFILE AS INDICATOR OF CLINICAL REMISSION TO TNF INHIBITORS IN PATIENTS WITH RHEUMATOID ARTHRITIS}

Borja Hernández-Breijo ${ }^{1}$, Israel Nieto-Gañán ${ }^{2}$, Cristina Sobrino ${ }^{3}$, Victoria NavarroCompán ${ }^{1,4}$, Ana Martínez-Feito ${ }^{1,5}$, Carlota García-Hoz ${ }^{2}$, Paloma LapuenteSuanzes $^{2}$, Javier Bachiller-Corral ${ }^{3}$, Gemma Bonilla ${ }^{1,4}$, Cristina Pijoan Moratalla ${ }^{3}$, Garbiñe Roy ${ }^{2}$, Mónica Vázquez ${ }^{3}$, Alejandro Balsa ${ }^{1,4}$, Luisa María Villar ${ }^{2}$, Dora Pascual-Salcedo ${ }^{1}$, Eulalia Rodríguez-Martín ${ }^{2}$, Chamaida Plasencia ${ }^{1,4}$ ${ }^{1}$ Immuno-Rheumatology research group, IdiPaz. La Paz University Hospital, Madrid, Spain; ${ }^{2}$ Immunology Department. Ramón y Cajal University Hospital and IRYCIS, Madrid, Spain; ${ }^{3}$ Rheumatology Department. Ramón y Cajal University Hospital and IRYCIS, Madrid, Spain; ${ }^{4}$ Rheumatology Department. La Paz University Hospital, Madrid, Spain; ${ }^{5}$ Immunology Department. La Paz University Hospital, Madrid, Spain

Background: Rheumatoid arthritis (RA) is a chronic inflammatory disease with the typical characteristic of synovitis of small-sized and medium-sized joints that leads to cartilage and bone damage. TNF inhibitors (TNFi) are widely used for the treatment of rheumatoid arthritis (RA) however, there are still no objective indicators of clinical response to TNFi therapy.
Objectives: To analyse the change of peripheral blood mononuclear cells (PBMC) profile after 6 months $(\mathrm{m})$ of treatment with $\mathrm{TNFi}$ in order to find cellular indicators of response.

Methods: Prospective bi-center pilot study including 100 RA patients receiving TNFi therapy. PBMC were isolated from patients at baseline and $6 \mathrm{~m}$ of treatment, and were analysed by flow-cytometry. Clinical activity at baseline and $6 \mathrm{~m}$ of TNFi treatment was assessed by DAS28. Clinical remission (DAS28 $\leq 2.6$ ) after $6 \mathrm{~m}$ of treatment was considered as optimal response. The association between clinical remission and the percentage of change $(\Delta, 6 \mathrm{~m}-0 \mathrm{~m})$ within each PBMC subset was analysed through univariate logistic regression model (odds ratio; $95 \% \mathrm{Cl} ; \beta$; $\mathrm{p}$-value). All the analyses were adjusted by sex, age, disease duration, concomitant-methotrexate, seropositivity (ACPA and/or Rheumatoid factor) and baseline-DAS28.

Results: Demographic characteristics before starting TNFi therapy are shown in Table 1. After $6 \mathrm{~m}$ of TNFi treatment, $40 \%$ patients achieved clinical remission. Decreased percentage of B cells $(\Delta \mathrm{CD} 19+)$ was found after $6 \mathrm{~m}$ of $\mathrm{TNFi}$ treatment in optimal responders, while suboptimal res ponders did not show differences with the baseline (OR: $0.78 ; 95 \% \mathrm{Cl}$ $0.63-0.97 ; \beta$ : $-0.25 ; \mathrm{p}: 0.027$ ) (Figure 1 ). This effect was essentially owing to a reduction of naïve $B$ cells (OR: $0.76 ; 95 \%$ IC: $0.62-0.94 ; \beta$ : -0.27 $\mathrm{p}$ : 0.011) (Figure 1). No significant association was found between the other PBMC subsets (monocytes, NK cells, CD4+ T cells and CD8+ T cells) and clinical remission (Figure 1).

Table 1

\begin{tabular}{lc}
\hline Baseline patients' characteristics & Total patients $\mathbf{( n = 1 0 0 )}$ \\
\hline Age (years); mean $\pm S D$ & $53 \pm 13$ \\
Female; $\mathbf{n}(\%)$ & $84(84)$ \\
Disease duration (years); median (IQR) & $8(4-12)$ \\
Rheumatoid factor positive; $\mathbf{n}(\%)$ & $77(77)$ \\
ACPA positive; $\mathbf{n}(\%)$ & $83(83)$ \\
Smoking habit; $\mathbf{n}(\%)$ & \\
non-smoker & $46(46)$ \\
smoker & $20(20)$ \\
ex-smoker & $34(34)$ \\
Body mass index (kg/m²); median (IQR) & $24.8(22.9-29.6)$ \\
DAS28; mean $\pm S D$ & $4.8 \pm 1.2$ \\
Previous TNFi treatment; $\mathbf{n}(\%)$ & $13(13)$ \\
TNFi type; $\mathbf{n}(\%)$ & $13(13)$ \\
Monoclonal antibodies & $55(55)$ \\
Etanercept & $45(45)$ \\
Concomitant csDMARD; $\mathbf{n}(\%)$ & $96(96)$ \\
Only Methotrexate (MTX) & $51(51)$ \\
Only other csDMARDs (OD)* & $18(18)$ \\
MTX + OD & $27(27)$ \\
\hline * Other csDMARDs: leflunomide, sulphasazine
\end{tabular}

* Other csDMARDs: leflunomide, sulphasalazine, hydroxychloroquine

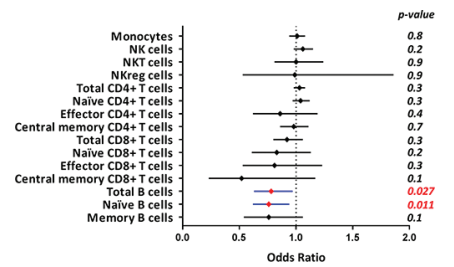

Figure 1. Association between the percentage of change ( $\triangle \mathrm{PBMC}, 6 \mathrm{~m}-0 \mathrm{~m}$ ) within each PBMC subset and the clinical remission. Univariate logistic regression analysis was performed for each PBMC subset. The analyses were adjusted by sex, age, disease duration, concomitant-methotrexate, seropositivity and baseline-DAS28. The percentage of changes $(\Delta, 6 \mathrm{~m}-0 \mathrm{~m})$ in total $B$ cells and in naïve $B$ cells were independently associated with the clinical response. No association was found in other PBMC subsets.

Conclusion: Our results suggest that B cells may be useful as a cellular indicator of response to TNFi in RA patients.

Acknowledgement: ISCIII (PI16/00474; PI16/01092)

Disclosure of Interests: Borja Hernández-Breijo: None declared, Israel Nieto-Gañán: None declared, Cristina Sobrino: None declared, Victoria Navarro-Compán: None declared, ANA MARTíNEZ-FEITO: None declared, Carlota García-Hoz: None declared, Paloma Lapuente-Suanzes: None declared, Javier Bachiller-Corral: None declared, Gemma Bonilla: None declared, Cristina Pijoan Moratalla: None declared, Garbiñe Roy: None declared, Mónica Vázquez: None declared, Alejandro Balsa Grant/research support from: Abbvie, Pfizer, Novartis, BMS, Nordic, Sanofi, Consultant for: Abbvie, Pfizer, Novartis, BMS, Nordic, Sanofi, Sandoz, Lilly, Paid instructor for: Pfizer, Speakers bureau: Pfizer, Novartis, UCB, Nordic, Sanofi, Sandoz, Lilly, Luisa María Villar: None declared, DORA 